\title{
As festividades dançantes no Clube Curitibano: os bailes como elemento da cultura física (1881-1914)
}

\author{
Dancing meetings at Club Curitibano: the balls as an element \\ of physical culture (1881-1914)
}

Las festividades danzantes en el Club Curitibano: Ios bailes como elemento de la cultura física (1881-1914)

\author{
Leonardo do Couto Gomes \\ Orcid: https://orcid.org/0000-0002-8866-2054 \\ Mestrado em Educação, Universidade Federal do Paraná, Curitiba, Brasil, \\ leo_gomes.97@hotmail.com \\ Evelise Amgarten Quitzau \\ Orcid: https://orcid.org/0000-0001-9789-6488 \\ Instituto Superior de Educación Física, Centro Universitario Paysandú da \\ Universidad de La República, Uruguai. eveliseaq@yahoo.com.br \\ Marcelo Moraes e Silva \\ Orcid: https://orcid.org/0000-0001-6640-7952 \\ Programas de Pós-Graduação em Educação e Educação Física, Universidade \\ Federal do Paraná, Curitiba, Brasil,moraes_marc@yahoo.com.br
}

Received on 21/02/2020 - Approved on 19/03/2020

\section{Resumo}

Os bailes sociais foram atividades presentes nas principais cidades brasileiras do século XIX. Nesse sentido, o presente artigo foi norteado pela seguinte problemática de pesquisa: Como ocorreu a implementação das festividades dançantes no Clube Curitibano entre os anos 1881-1914? Como fontes, foram utilizados jornais e revistas publicados em Curitiba no período. As análises apontam que a inserção dos bailes no Clube investigado ocorreu com intenção distintiva das danças realizadas em outros espaços. Percebe-se que, por meio dos bailes, a agremiação buscava um refinamento da educação corporal dos associados. Conclui-se que a implementação da dança no Clube Curitibano era realizada sob moldes regrados e controlados, a ponto de esta ter parcela significativa na pedagogia corporal de seus sócios.

Palavras-chave: Dança; Clubes; Cultura física; Curitiba; Educação do corpo. 


\begin{abstract}
Social balls were frequent activities in the main Brazilian cities of the nineteenth century. They were considered important elements of social distinction, therefore social clubs played an important role in diffusing and improving such festivities. In this sense, this paper is guided by the following question: how were dancing festivities introduced in Club Curitibano, between 1881 and 1914? The sources were newspapers and magazines published in Curitiba, in the established period. The analysis points out that the introduction of dancing activities occurred as a means to distinguish this club from dances that were performed in other spaces in Curitiba. It was possible to notice that this club aimed at the refinement of the bodily education of its members, dictating the correct dancing standards. One concludes that dancing was introduced in Club Curitibano under a regimented and controlled form of physical culture, having great significance in the corporal pedagogy of the club's members.
\end{abstract}

Keywords: Dance; Clubs; Physical culture; Curitiba; Education of the body.

\title{
Resumen
}

Los bailes eran actividades presentes en las principales ciudades brasileñas del siglo XIX. En este sentido, el presente artículo fue guiado por la siguiente problemática de investigación: ¿Cómo ocurrió la implementación de las festividades de baile en el Club Curitibano entre 1881-1914? Como fuentes, utilizamos periódicos y revistas publicados en Curitiba en el período. Los análisis indican que la inserción de los bailes en el Club investigado se produjo con la intención distintiva de los bailes realizados en otros espacios. Se observa que, a través de los balones, la asociación buscó un refinamiento de la educación corporal de los miembros. Se concluyó que la implementación de la danza en el Club Curitibano se realizó de manera regulada y controlada, en la medida en que tuvo una participación significativa en la pedagogía corporal de sus miembros.

Palabras-clave: Baile; Clubes; Cultura física; Curitiba; Educación del cuerpo.

\section{Introdução}

Weber (1988) e Vigarello (1999), ao analisarem o contexto francês, assinalam que as associações tiveram papel central no desenvolvimento de mentalidades inéditas em relação ao corpo e a seus processos de educação. Por sua vez, Melo (2001), ressalta que os clubes no Brasil, na virada do século XIX para o XX, se tornavam um importante local para o desenvolvimento do ideário urbano, que acabou se consolidando como um espaço de distinção social. $\mathrm{O}$ autor ainda argumenta que o próprio uso do termo club, oriundo da língua inglesa, indicava um sentido de lugar no qual se encontravam cavalheiros. Com base nessa perspectiva, as associações seriam um espaço de encontro entre iguais.

O Clube Curitibano - enfoque analítico do presente artigo - também constituía um espaço específico de sociabilidade envolvido em um discurso de pertencimento de seus membros e, consequentemente, de distinção. Tal fato 
torna-se evidente com a fundação do Clube em 25 de setembro de 1881, pelo Comendador Ildephonso Pereira Correira (Barão do Serro Azul), comerciante de erva-mate e madeiras e pioneiro do setor industrial de transporte e negócios bancários em Curitiba. Diante disso, menciona-se que a associação era constituída inicialmente por integrantes luso-brasileiros da elite política, econômica e letrada do Paraná.

O lema central da instituição era Malum non admitte (não se admite o mal), frase que está estampada no escudo da instituição até os dias atuais. Essa citação tinha como intuito demonstrar o espírito moral no qual se fundou a agremiação, evidenciando que a jovem entidade se estabelecia sob o mais puro sentimento de afetividade e respeito para a elite familiar paranaense, sendo, portanto, um lar recatado onde não se admitiria nem ao menos o vislumbre da malícia e da maldade.

A fundação do Clube estava intimamente relacionada com o desejo de parte da elite curitibana em ter um local separado dos clubes sociais criados por estrangeiros, como o Clube Gesangverein Germânia, fundado em 1869 por imigrantes alemães (Moraes e Silva, 2011). Outro anseio dos membros do Clube Curitibano era o de possibilitar um convívio amistoso com fins recreativos, culturais e morais (Pastre, 2009). Porém, a emergência de outras agremiações com esses aspectos, conforme aponta Moraes e Silva (2011), ia além da vontade de se distinguir dos clubes já criados e de uma sociabilidade entre cavalheiros, indo ao encontro também com o processo de urbanização que perpassava a capital paranaense na época. $O$ autor indica que, nesse momento, emergiram diversos ambientes recreativos na cidade, como cafés, teatros, parques, além de clubes sociais.

A inserção desses novos espaços na capital paranaense advinha de um desejo de urbanização que a cidade almejava realizar, fato que possibilitou a emergência de novas gestualidades, dentre as quais se destacam as voltadas aos fins recreativos e culturais, que já se materializavam em solo europeu como comportamentos modernos e civilizados (Vigarello, 1999). Entre essas condutas, sobressaem-se as relacionadas à cultura física, que, conforme apontam Moraes e Silva e Quitzau (2018), era uma tentativa de estabelecer condutas modernas na sociedade curitibana do período.

Kirk (1999), ao analisar o contexto europeu, afirma que o conceito de cultura física foi amplamente utilizado nos séculos XIX e XX. Posteriormente, Moraes e Silva (2011), Dogliotti (2014), Scharagrodsky (2014), Reggiani (2016), Furtado, Quitzau e Soares (2018), Moraes e Silva e Quitzau (2018) e Moraes e Silva, Quitzau e Soares (2018) utilizaram-se desse conceito em pesquisas historiográficas no contexto sul-americano. Os autores compreendem a cultura física como uma profunda rede de significados que permite análises multidimensionais que ultrapassam a dimensão biológica. Ao considerar que, na maioria das vezes, as distintas práticas corporais são pensadas a partir dessa rede de significados, a aplicabilidade do termo em pesquisas voltadas ao respectivo período e temática torna-se bastante coerente.

Existem fortes indícios de que, no caso curitibano, a definição de cultura física ascendeu como uma importante maneira de solidificar as práticas físicas nas instituições da cidade, fortalecendo as agremiações e os indivíduos que as frequentavam (Moraes e Silva, 2011; Moraes e Silva; Quitzau, 2018; Moraes e Silva; Quitzau; Soares, 2018). 
Moraes e Silva e Quitzau (2018) salientam que tal conceito possibilita a operação com discursos voltados ao corpo a partir de três manifestações: divertimentos, ginásticas e esportes. Sendo assim, a utilização da noção de cultura física possibilita identificar amplos repertórios de práticas e construções discursivas sobre o corpo, estabelecidos por diferentes grupos sociais, indivíduos e estruturas. Entretanto, para realmente efetivar esse novo modelo urbano que tinha a cultura física como um de seus constituintes, não bastava apenas a transformação dos clubes, era necessário transformar, também, toda a cidade de Curitiba.

Percebe-se, portanto, que Curitiba passava por um processo de constituição de mecanismos institucionais para se adaptar às novas formas de comportamento presentes na cidade, entre essas, as práticas voltadas ao cultivo de uma cultura física (Moraes e Silva, 2011; Moraes e Silva; Quitzau, 2018). Nesse sentido, pretende-se elaborar um olhar acerca dos primeiros resquícios de elementos da cultura física no interior do Clube Curitibano.

As fontes acionadas apresentam os bailes sociais como atividades bastante presentes na associação. Pereira, (2017), ao estudar o associativismo recreativo através dos clubes sociais na cidade do Rio do Janeiro na primeira metade do século XIX, argumenta que a dança nesse momento era um divertimento central na então capital brasileira, sendo um momento utilizado para fuga do cansaço do trabalho, mas, também palco de relações interpessoais políticas, onde cavalheiros aproveitavam este espaço para trocar diversas informações.

Roquigny (2011), ao analisar os divertimentos dançantes na cidade de Montreal, no Canadá, indica que tais festividades eram consideradas um símbolo de modernidade e um elemento central para o desenvolvimento de gestualidades estimadas como civilizadas. Logo, a implementação da cultura física via festividades dançantes ganhava valor para aqueles que buscavam o progresso urbano, interesse claramente intentado pelo Clube Curitibano.

Nesse sentido, o presente artigo parte da seguinte problemática de pesquisa: Como ocorreu a implementação das festividades dançantes no Clube Curitibano entre os anos 1881-1914? A partir de tal interrogação, elenca-se o objetivo geral: investigar a implementação dos bailes no Clube Curitibano na temporalidade delimitada. Já os objetivos específicos são os seguintes: a) Caracterizar como o Clube Curitibano destacava discursos para o cultivo de uma cultura física voltada à dança; b) Evidenciar como ocorriam as primeiras práticas voltadas aos elementos dançantes no interior da agremiação; c) Demonstrar como o Clube Curitibano se inseria no processo de urbanização da capital paranaense com contribuições para o fomento de civilidade e bons costumes por meio do desenvolvimento dos bailes sociais.

O recorte temporal deste estudo corresponde ao período entre 1881, ano de fundação do Clube Curitibano, e 1914, marco que está intimamente relacionado com a hipótese de que o discurso da cultura física por meio da dança já se encontrava solidificado no interior do Clube. Torna-se ainda válido lembrar o porquê da escolha do Clube Curitibano como objeto investigativo. Tal predileção se deu em razão da representatividade que o Clube tem na cidade de Curitiba, contando atualmente com mais de 30 mil associados e cinco sedes, sendo considerado um dos mais tradicionais do Paraná (Dorfman, 2019; Pilato, 2018). 


\section{Fontes}

O material selecionado constituiu-se de documentos que se relacionam diretamente com o Clube Curitibano e a emergência de discursos voltados à cultura física existente no interior da referida instituição. Selecionaram-se fontes escritas retiradas de revistas e jornais dentro da temporalidade delimitada. A primeira fonte selecionada trata-se da Revista Clube Curitibano - publicação criada em 1890, que perdura até os dias atuais. A revista tinha ${ }^{1}$ edições quinzenais e fornece importantes vestígios do processo de desenvolvimento da cultura física no Clube ${ }^{2}$. Outros documentos selecionados foram os jornais que circulavam em Curitiba no período em questão.

Um dos jornais selecionados foi o "Dezenove de Dezembro". Tal periódico foi o primeiro a ser publicado no Paraná, circulando por 36 anos, desde 1854 até o seu fechamento em 1890, sendo o principal jornal em circulação em Curitiba no período de seu funcionamento. Pezzole (2006) explica que a publicação nasceu principalmente pela necessidade de consolidar Curitiba como capital e que, junto à imprensa escrita, novas infraestruturas urbanas passaram a ser implantadas na cidade, tais como teatros, escolas, clubes etc. As páginas do "Dezenove de Dezembro" eram ocupadas por publicações de editais de compras, convocações de jovens para o serviço militar, decretos, concessão de licenças para servidores, nomeações e exonerações, dividindo espaço também com notícias relacionadas a comércio e economia, além de, em alguns momentos, serem encontrados alguns registros sobre os elementos da cultura física.

Outro jornal elencado foi o "A República". Esse periódico foi fundado em 15 de março de 1886 e foi extinto em 1930. Segundo Corrêa (2009), foi a publicação de maior repercussão local, por sua importância como primeira folha republicana da capital paranaense. A valorização e a massificação do jornal estavam em sintonia com um discurso de fundação de uma República, assunto fortemente avivado naquele período.

O último jornal analisado foi o "Diário da Tarde". Segundo Cunha Filho (1998), esse periódico circulou na cidade entre os anos de 1899 a 1940. Era um canal de comunicação de tendência liberal e anticlerical, que procurava por intermédio de seu conteúdo, cobrar do poder público comportamentos coerentes com os pressupostos liberais, julgados como essenciais para possibilitar o progresso e a modernização da cidade, afirmando comumente em suas linhas os clubes sociais e esportivos como espaço contribuinte para o desenvolvimento das práticas voltadas a cultura física em Curitiba.

Salienta-se que a escolha dos jornais se deu pelo fato de os estes retratarem, em muitos momentos, acontecimentos realizados no interior do Clube Curitibano. Torna-se importante salientar, conforme aponta Luca (2008), que os periódicos eram a principal forma de divulgação da época e, por isso, são importantes fontes para a realização de trabalhos historiográficos. Além disso, segundo Benvenutti (2004), a imprensa passava a ditar os anseios da elite curitibana, postulando o que era correto ou não para o desenvolvimento da cidade.

Os materiais referentes à Revista Clube Curitibano foram encontrados no acervo da própria instituição. Já os jornais foram acessados no acervo da Biblioteca Pública do Paraná, localizada na cidade de Curitiba, ou através da interface on-line da Hemeroteca Digital da Biblioteca Nacional. 


\title{
Entre o controle dos fandangos populares e a formulação dos bailes
}

\begin{abstract}
Sabemos que é tenção da directoria do Club, proporcionar todos os mezes aos seus associados um sarau identico, com conferencias litterarias etc., pelo que louvamos tão proveitosa iniciativa (A Republica, 1907, Ed. 10, p. 2.).
\end{abstract}

O hábito de realizar bailes era algo presente em Curitiba antes mesmo da constituição do Clube Curitibano. Leandro (2007), indica que os primeiros divertimentos dançantes encontrados na cidade, denominados fandangos e batuques, caracterizavam-se por serem festividades realizadas em espaços menos estruturados e normalmente fora do âmbito urbano (chácaras, sítios e vielas). O autor salienta que eram realizados por indivíduos de baixos extratos sociais - lugares nos quais a "bebedeira" e "safadeza" eram componentes rotineiros - fatores que faziam com que tais recintos não fossem considerados contribuintes para o desenvolvimento de Curitiba como a capital do Paraná, pois não se assemelhavam com os discursos modeladores que a elite oitocentista paranaense almejava e, portanto, representavam um mal a ser extirpado da sociedade.

Segundo Pereira (1996), a perseguição aos bailes de fandango, em meados do século XIX, estava intimamente relacionada ao interesse das autoridades em resguardar o caráter religioso e familiar dos indivíduos, mas, além disso, havia um anseio de formular uma cultura amparada em costumes europeus. $\mathrm{O}$ apagamento dessas práticas populares era um desejo das classes mais abastadas, pois acreditavam que os fandangos e batuques eram festividades que não potencializavam as aspirações civilizatórias. Sendo assim, os bailes populares eram considerados um mal, ou seja, algo que deveria ser suprimido do seio de uma cidade que almejava alcançar o status de um moderno centro urbano.

Westphalen (1983) aponta que em 1792 já havia indícios de preocupações da Câmara Municipal em proibir a realização dos fandangos em Curitiba. De fato, matérias de diversas naturezas apontavam que as festividades populares sofreram diversas repressões por parte das autoridades. Uma das alternativas para conter os fandangos e batuques foi a elaboração de legislações regulamentando os festejos, como pode ser visualizado nos artigos do decreto $\mathrm{N}$. 96 de 11 de abril de 1863:

Art. 12. Para se fazer fandango ou batuque, dentro ou fora das povoações, é preciso que preceda licença da camara pela qual pagará, quem a pedir, 3800 . Esse divertimento deve ser feito observando-se todo o respeito á moral e aos bons costumes.

Os infractores (alem do dito imposto de licença sendo o autor ou promotor do divertimento, e alem da mais penas em que incorrem pelas leis, no caso de offensaa moral e bons costumes) sofferão a multa de 10800 , ou prisão por tres dias, não podendo ou não querendo pagal-a. Nas reincidencias se applicarão os ditas penas em dobro. 
Art 14. Os donos ou chefes das casas onde se fizer o divertimento são obrigados a dispersar o ajuntamento, dando aquelle por findo si se manifestar algum disturbio, que possa occasionar másconsequencias. Não a fazendo soffrerão, alem das mais penas em que incorrerem, 30000 de multa, ou na falta desta prisão por quatro dias. Nas reincidencias incorrerão no dobro das penas (Dezenove de Dezembro, 1863, Ed. 375, p. 2.).

Nota-se que organismos regulatórios e punitivos estavam sendo implementados na cidade. A constituição de tais dispositivos significava uma tentativa de regrar as práticas populares e educar os corpos dos indivíduos que frequentavam esses espaços. O objetivo era conter gestualidades ditas como imorais e incivilizadas. Nesse sentido, era comum a impressa local relatar de forma pejorativa as ocorrências dos fandangos:

No dia 3 do corrente, no logar denominado Ferraria, districto desta capital, por occasião de um fandango, um individuo conhecido por Antonio da Rondinha e o escravo de Mariano de Almeida Torres, de nome Silverio, espancaram a Joaquim de Sant'anna a ponto de ficar muito maltratado. Foram, pelo Dr. Chefe de policia, dadas as necessarias providencias afim de ser feito o corpo de delicto e inquerito policial (Dezenove de Dezembro, 1873, Ed. 1403, p. 3.).

O sr. commisario de policia do termo de S. José da Bôa Vista communicou, em officio, ao sr, dr. chefe de policia que, no lugar denominado "Serrado", José Ribeiro Lopes, conhecido também por José Lourenço, em um fandango, assassinará em tres facadas, a Pedro Roza Góes, vulgo Pedro Christino, em cuja casa se effectuara a festa. A autoridade respectiva iniciou o inquerito e procedeo ao exame de corpo de delicto no cadaver. O homicida conseguio evadir-se (A Repuplica, 1901, Ed. 149, p. 1.).

Percebe-se que a imprensa construía a imagem de que a desordem e a violência pairavam sobre os fandangos e batuques. As críticas às festividades populares eram frequentes nos jornais curitibanos, nos quais não se poupavam farpas aos fandangos:

Há allemães que gostam de fandangos como melhor brasileiro; e o fandango não passa de um grosseiro uso popular em que o moral nada aproveita. Não maldigo da cousa, senão do modo. Há brasileiros que não tomam o gosto de ver sua habitação, desolada pela nobreza, bafejada ao menos pela ordem e pelo arranjo nessa mesma pobreza (Dezenove de Dezembro, 1866, Ed. 657, p. 2.).

De acordo com Martins e Luca (2010), a crítica da imprensa brasileira aos acontecimentos cotidianos e corriqueiros, desde meados do século XIX, além de bastante frequente, era muito contundente. As autoras afirmam que a publicidade proporcionada pelos jornais se articulava com as demandas da nova vida urbana. Nesse sentido, enfatizar em suas páginas o desejo dos dirigentes era uma forma de os periódicos se manterem nos trilhos do progresso urbano. Ao analisar esse contexto, Sevcenko (1983) salienta que as letras, nesse período, tinham a missão de estruturar a sociedade brasileira aos moldes da modernidade europeia, 
produzindo, por meio dos escritos, principalmente os divulgados nos jornais impressos, um esquecimento do Brasil rústico e rural.

A missão literária levantada por Sevcenko (1983) também se mostrou presente em Curitiba. Uma das esferas que o mundo das letras curitibano dedicou especial atenção foi em relação aos batuques e fandangos. Dessa maneira, é possível afirmar que a formulação de um local específico para a materialização das práticas dançantes representava um símbolo do progresso. A constituição da "Sociedade Harmonia", que almejava se tornar um requintado e especializado espaço de bailes, se estruturou um ano após Curitiba se tornar a capital da província e idealizava ser lócus de desenvolvimento dos bons costumes e de valores considerados civilizados:

\begin{abstract}
Fallaremos da sociedade de bailes, que se trata de estabelecer n'esta capital. Tem por nome, por divisa, por fim, a - HARMONIA -: o pensamento da sua instalação é uma consequência da actual ordem das couzas (...) na nossa opinião uma sociedade de bailes, organisada, com esse pensamento, muito concorrerá para estreitar as relações íntimas entre os diversos grupos da grande família paranaense (...) Sofregos esperemos os primeiros bailes da HARMONIA! Em meio dos prazeres de um sarão, as horas vôam como os dias de felicidade, os pensamentos tristem desaparecem, como a branca geada aos raios tépidos do sol (...) Quanto não é grato ao pobre funccionariopublico, ao negociante, ao lavrador, depois de um dia de prosaico trafego de vida, passar algumas horas divertidas no meio de uma sociedade de baile! Todos os motivos de desgosto, que se lhe tenha impressionado durante a vida desaparecem ao transpor o limiar do salão. Faremos votos para a duração de um divertimento, que não concorre pouco para os melhoramentos moraes de que tanto carecemos (Dezenove de Dezembro, 1854, Ed. 7, p. 1).
\end{abstract}

A nota apresenta com detalhes a necessidade de instituir espaços adequados e regrados para a realização de bailes. Sêga (2001) lembra que, nesse momento, uma série de espaços e serviços urbanos também se estruturava na cidade (galerias fluviais, bondes elétricos, iluminação pública), além de espaços de sociabilidade, como cafés, clubes, praças, teatros, delineamentos estes, conforme aponta Moraes e Silva (2011), fundamentais na consolidação dos elementos da cultura física. Cabe ainda destacar que a notícia também evidenciava os aspectos morais exigidos dos indivíduos que desejassem fazer parte desses divertimentos.

Roquigny (2011), ao estudar o contexto de Montreal entre os anos de 1870 e 1914, indica um cenário bastante semelhante ao encontrado em Curitiba, visto que os eventos de dança realizados na cidade canadense foram iniciados principalmente por indivíduos e associações ligadas às elites locais. A autora indaga que, quando se tratava de organizar danças fechadas ao público, as instalações das associações apareciam como os espaços apreciados pelos indivíduos que dispunham de meios para construção de infraestruturas adequadas, assegurando a tais eventos um caráter grandioso e de acesso limitado somente a convidados.

Em Curitiba encontram-se indícios de produzir esse mesmo sentimento de distinção social por meio dos bailes, visto que a elite curitibana passava a indicar que o fandango deveria ser evitado e o baile valorizado, conforme advertiam rotineiramente os jornais do período: 
O artigo 147 do codigo de posturas municipaes exige 40000 de licença para que o caipira possa espichar a canella no abracadabrante sapateio de fandango. Ora o fandango segundo o Sr. José de Moraes é um baile popular da roça. $O$ baile por isso mesmo deve ser um fandango popular da cidade. $O$ fandango é a viola, é a fercida é os desafios. O baile é a banda musical, é o cognac e etc, é o desfechar dos rewolvers surdos engatilhados pelo olhar... O fandango é a natureza. O baile é a arte. Pôem-se uma finta no fandango e no baile... No baile diz se - a lei é egual para todos! E é (Dezenove de Dezembro, 1884, Ed. 217, p. 2.).

A passagem evidencia que a emergência de associações dançantes possibilitou à imprensa local realizar comparações entre os bailes sociais e os batuques e fandangos, apontando os primeiros como práticas corretas e os segundos como algo a ser extirpado da sociedade. Afinal, os bailes populares não estavam em sintonia com o ideário urbano, algo bem diferente dos anseios que o discurso da cultura física almejava. Suas atividades, conforme lembram Moraes e Silva e Quitzau (2018), precisavam estar intimamente vinculadas a um discurso institucionalizado ligado diretamente aos ditames da modernidade.

Nessa temporalidade em Curitiba ocorreu uma série de medidas ligadas à produção de uma maior civilidade na cidade. O autor aponta que foram proibidos o porte de arma, jogo a dinheiro, palavrões em via pública, escritos obscenos nas paredes e muros, circulação de pasquins, judas, cantorias de rua e gestualidades populares como a capoeira e as festas fandangosas. As censuras a essas gestualidades específicas, como ressalta Moraes e Silva (2011) e Moraes e Silva e Quitzau (2018), não estavam em sintonia com o novo modelo urbano que se estruturava em Curitiba, pois, conforme aponta o autor, era necessário educar e disciplinar as sensibilidades segundo os padrões de gestualidades consideradas civilizadas.

Melo (2014), ao pesquisar o contexto da cidade do Rio de Janeiro, indica que a emergência dos bailes sociais provocou uma necessidade de desenvolvimento e aprendizagem de novas maneiras de se comportar, que deveriam ser proporcionadas principalmente pela família e escola. Porém, em Curitiba, com a estruturação do Clube Curitibano, indica-se que a entidade também se configurou como uma instituição que proporcionava esses princípios educativos por meio de divertimentos como os bailes.

\section{Pedagogizando os corpos e fortalecendo o espírito: A dança como uma ferramenta educacional}

Chalhoub (2012) afirma que os bailes eram um divertimento reconhecido pelos países desenvolvidos, que possibilitavam um convívio social digno e que poderiam também proporcionar a incorporação de hábitos considerados saudáveis. A dança poderia também ser uma forma de acesso às benesses do discurso da cultura física. Saber dançar passava a ser uma necessidade, no entanto não poderia acontecer de qualquer forma, mas sim com base em estilos considerados modernos. A cidade de Curitiba passava então a ganhar espaços especializados no ensino de gestualidades dançantes: 


\section{ESCOLA DE DANÇAS}

N'um curso bi-mensal ensino as seguintes 17 danças:

De ronda: $1^{\circ}$ Valsa de Vienna; $2^{\circ}$ Valsa franceza; $3^{\circ}$ Valsa allemã; $4^{\circ}$ Valsa bohemia.

De salão: $5^{\circ}$ Quadrille; $6^{\circ}$ Quadrillemonstre; $7^{\circ}$ Quadrille de la lour; $8^{\circ}$ Cotillon Danças polocas de ronda:

$9^{\circ}$ PolkaVersoirenne; $10^{\circ}$ PolkaParisienne; $11^{\circ}$ PolkaMazurka; $12^{\circ}$ Polka Galope; $13^{\circ}$ Cuiavienne; $14^{\circ}$ Oreck;

De Figura: $15^{\circ}$ Polonaise; $16^{\circ}$ cracovinne; $17^{\circ}$ Muzar.

O curso encerra 24 lições, sendo tres por semana. Todos os sabbados lições em comum. Recebe-se inscripções na sala das danças. Praça Santos Andrade n. 90. Esquina da Rua João Negrão todos os dias das 10 horas até o meio dia e das 6 até a 7 da noite. Quem desejar lições em casa particular, dirija-se ao mestre de danças (Diário da Tarde, 1908, Ed. 2892, p. 2.).

As escolas de dança forneciam um ar de especialização, visto que seus mestres eram considerados entendidos no assunto. Salienta-se que o aperfeiçoamento de uma prática e a formação de experts possibilitavam ainda mais a valorização das atividades voltadas ao cultivo de elementos da cultura física. Nos salões do Clube Curitibano os estilos predominantes eram as valsas e as danças de quadrille, desse modo, saber como se portar durante uma dança passava a ser uma necessidade, principalmente para quem frequentava uma instituição de cunho distintivo como o Clube Curitibano.

Melo (2014), lembra que a dança proporcionava um contato físico considerado inusitado naquele período histórico. Nesse sentido, o autor salienta que saber se portar de forma harmônica era de extrema valia, pois o oposto disso era visto como maléfico e indesejado. Percebe-se que as atividades presentes nos salões de bailes possibilitavam uma nova forma de sociabilidade, agora mais centrada em um corpo a corpo, em que a forma de se vestir, o domínio gestual das técnicas de dança e principalmente o controle de si em relação ao outro eram elementos necessários.

Moraes e Silva (2011) indica que os salões de bailes curitibanos objetivavam ser um espaço para os corpos ostentarem os códigos de civilidade, um local para mostrar o comportamento ideal, o gosto "correto", ou seja, eram locais idealizados que possibilitavam o estabelecimento do anseio de distinção almejado por instituições como o Clube Curitibano. Segundo Bourdieu (2007), o motor de diversas ações sociais seria a busca por uma distinção, de forma que existir em um espaço é diferir-se, ser classificado e ao mesmo tempo ser classificante, aspectos que a estruturação de um clube ou associação, conforme indicam Vigarello (1999) e Roquiny (2011), possibilitam aos seus frequentadores alcançarem.

Diante disso, entende-se que os comportamentos tidos como apropriados e que eram fortemente avivados pelos jornais de Curitiba, muitas vezes ligados ao discurso da cultura física, eram próximos aos elementos de distinção levantados por Bourdieu (2007). O sociólogo francês descreve que a distinção é operacionalizada por um conjunto de práticas e de propriedades de um indivíduo ou grupo, funcionando como agentes práticos da transmutação das coisas em 
sinais distintos e distintivos, cujos comportamentos possibilitem que diferenças de ordem material se convertam em alterações simbólicas e vice-versa. Entretanto, considera-se que os novos gostos e maneiras de se comportar que vinham emergindo em Curitiba, cravados também no interior dos salões do Clube Curitibano, eram ostentados pela elite local.

Afinal, a expressão da cultura física, materializada na forma dos bailes, era baseada em costumes europeus. Os comportamentos do velho continente, conforme salienta Freyre (1974), estavam sendo fortemente avivados nas principais cidades do Brasil do século XIX, fazendo com que as modas europeias fossem adotadas com exageros, especialmente por meio de elementos como técnicas administrativas, estilos literários e inovações pedagógicas.

Entre tais invocações europeias, também estavam aquelas relacionadas à cultura física e que também foram materializadas no Clube Curitibano. Todavia, para que os comportamentos modernos pautados na cultura física viessem a se estabelecer na entidade, as festividades dançantes precisavam primeiramente ser aceitas e valorizadas socialmente. Para tal efetivação, os bailes deveriam ser vistos como divertimentos úteis, realizados em espaços regulados por um dispositivo institucional, visto que, conforme adverte Moraes e Silva (2011), a institucionalização foi um ponto primordial para o fortalecimento dos elementos da cultura física na capital paranaense.

O Clube Curitibano foi um espaço que se adequou a uma lógica institucional. A agremiação, ao aderir a incorporação de alguns divertimentos, iniciou um novo marco no que se refere a uma prática festiva, dando um caráter grandioso ao que vinha sendo realizado até então na cidade. Em virtude dos vastos salões que tinha em suas instalações, novos modelos gestuais se estabeleceram no interior da agremiação:

\begin{abstract}
Esta conceituada sociedade, que conta o numero de festas que proporciona a seus associados, no forma do costume abrio hontem os seus salões realisando um dos mais animados bailes que temos assistido. A's 10 horas da noite era quasi impossivel 0 transito pelos amplos e confortaveis compartimentos destinados ás danças, onde se encontravam as mais distinctasfamilias da elite curitybana. (...) o animado jogo de conffetie lançaperfumes que tomou as maiores proporções, deixando os salões completamente atapetados de conffetis e impregnando o ambiente com as suaves exhalações de milhares de vidros de lança-perfumes, que se trocavam na hilariante e franca animação (Dezenove de Dezembro, 1888, s.p.).
\end{abstract}

Os bailes sociais do Clube Curitibano proporcionaram a emergência de novas gestualidades, fornecendo um algo a mais para as noites curitibanas, pois propiciavam uma peculiaridade significativa, uma vez que os indivíduos poderiam "ver e serem vistos", passando a serem símbolos da civilidade e da distinção social (Moraes e Silva, 2011). Nesse sentido, a materialização da cultura física por meio das festividades dançantes passava a ser um importante elemento para o desenvolvimento da entidade e o enaltecimento da dimensão urbana e moderna em Curitiba.

Um dos fatores que contribuiu para o desenvolvimento e o destaque das soirées na instituição foi a inovação nos divertimentos. O Clube passava a dar festas com temas inovadores, dentre esses um baile destinado somente às crianças:

History of Education in Latin America - HistELA, v. 3, e19729, 2020, p. 11 de 19 
O clube Curytibano festejará este anno a Alleluia com magnifico sarau dançante, a realizar-se sábado proximo nos seus fidalgos salões. No dia seguinte, domingo, haverá um baile infantil, diversão nova n'esta capital e que muito agradará os petizes curytibanos (A Republica, 1906, Ed. 87, p. 2.).

Nos salões do Club Curytibano teve lugar hontem um animado baile infantil, ao qual seguio-se um sarau dançante. $\mathrm{O} 2^{\circ}$ baile infantil foi mais um brilhante triumpho para a actual direcctoria que com tão louvavel esforço procura introduzir novos melhoramentos no Club. Das 5 horas da tarde as 8 e meia da noite a petizada dansou com grande enthusiasmo havendo uma pequena turma de alumnas da escola Jardim de infancia executado diversas evoluções e cantos que muito agradaram. Realisou-se em seguida o sarau dançante que se prolongou com grande animação até altas horas da madrugada ( $A$ Republica, 1906, Ed. 90, p. 2.).

A presença da criança nos salões de baile era frequente, tanto que existia uma temporalidade específica para o corpo infantil habitar o espaço dançante: das cinco da tarde às oito e meia da noite. Horário bem mais restrito se comparado ao dos adultos, visto que as festividades principais iam até as três da manhã. Percebe-se, então, que o Clube intentava educar tanto o corpo da criança quanto o do adulto. Melo (2018), ao se referir à sociedade fluminense desse período, enfatiza que a dança foi a prática corporal com mais destaque no que se refere a uma iniciativa de formação das crianças, sendo tratada como um elemento da cultura física capaz de pedagogizar os corpos. O autor ainda sinaliza que a conotação educacional dada à dança atingiu diretamente o ambiente escolar, tornando-se uma ferramenta auxiliar para a formação infantil. No entanto, em Curitiba verificou-se que a atividade dançante se tornou um projeto educacional do próprio Clube Curitibano.

\section{Especializando a dança, forjando o físico e os sentidos: Inovações gestuais e operacionais nas soirées}

As inovações do Clube diante das soirées não cessaram e uma questão para os bailes serem ainda mais valorizados foi a colaboração de uma entidade denominada Grêmio das Violetas:

Um grupo de mademoiselle o que ha de mais-chic na nossa sociedade, organizou uma sociedade recreativa denominada Gremio das Violetas, e a sua Directoria teve a gentileza de nos offertar com um convite para assistirmos a sua installação que se effectuará hoje, as 8 e meia da noite, na casa da rua Marechal Deodoro n. 46. Penhoramos por termos sido tão amavelmente distinguidos agradecemos a gentileza do convite (A Republica, 1894, Ed. 185, p. 1).

Enfatiza-se que o surgimento da respectiva agremiação, fundada em 1894, se deu justamente por representar o caráter inovador que a instituição almejava, trazendo aos divertimentos traços modernos e diferenciados, além de contribuir com o aprimoramento de um elemento da cultura física: a dança. Vaz (2004)

History of Education in Latin America - HistELA, v. 3, e19729, 2020, p. 12 de 19 
indica que as Violetas eram um grupo constituído exclusivamente por moças da alta sociedade curitibana, que se reuniam para promover eventos dançantes nos salões do Clube Curitibano. A autora aponta que, no início do século $X X$, a associação ficou conhecida como "a curitibana dos salões", fato que possibilitou às suas associadas se tornarem figuras marcantes nos bailes da cidade, pois ditavam as gestualidades corretas a serem praticadas nesses espaços: Informada e culta, sua associada deveria saber conduzir-se nos eventos sociais, servindo de adorno ao marido, ou dando resposta satisfatória às expectativas ansiosas dos pais (Vaz, 2004). Logo, o Grêmio das Violetas, constituído das graciosas senhoritas da elite curitibana, passou a trazer ainda mais sofisticação às noites de baile do Clube Curitibano:

Com toda pompa que é capaz um grupo de distinctas moças, como é o
Gremiorealisou-seante-hontem o esplendido baile annunciado por esta
delicada e brilhante associação de moças. Os salões do Clube
Coritibanoregorgitavam de socias e convidados, havendo grande animação e
magnificas toilets, destacando se as cores violacca e lilaz das vestes do
ruidoso grupo que compõe o Gremio das Violetas. Um explendor! (A
Republica, 1904 Ed. 185, p. 1.)

Percebe-se que foi por meio do Grêmio das Violetas que reverberaram os comportamentos tidos como elegantes nas noites do Clube, porém a valorização desses aspectos não era algo exclusivo ao Clube Curitibano. Melo (2014) indica que, no Rio de Janeiro, o apreço aos bailes estava intimamente relacionado a um discurso de que as atividades públicas de convivência interpessoal deveriam ser cada vez mais valorizadas em uma cidade que intentava se inserir em um ideário moderno. O autor destaca que uma alteração importante no dinamismo social carioca foi a crescente estruturação de comércios de luxo e entretenimentos, todos relacionados a uma sociedade civil em construção, que desejava "(...) expor publicamente seus símbolos de status e distinção” (Melo, 2014, p.753).

Os bailes passaram a ser realizados com mais frequência no Clube Curitibano e, assim, um divertimento regrado e institucionalizado anunciava para a sociedade curitibana que o progresso estava a caminho, além de ofertar aos associados a possibilidade de exibir as destrezas gestuais encarnadas em seus corpos por essa nova pedagogia corporal. Esse processo evidenciava para 0 restante dos indivíduos que 0 oposto disso seria considerado incorreto e indesejado:

\footnotetext{
Belissimas noites de festas deu-nos o conceituado Club Curytibano. Hoje findam as kermesses. Vamos ter a terceira noite de deslumbramentos feéricos, entre fascinações de pingentes facetados dos lustres em brasa, perfumarias suavisando o ambiente morno das salas, palpitares de corações enamorados, olhares fascetantes, sorrisos e vozes de moças e elegancia apurada de rapazes satisfeitos (A Republica, 1900, Ed. 18, p. 4.).
}

A incorporação de determinados códigos de conduta era um requisito importante não apenas para os membros do Clube Curitibano, e sim para toda a nova vida pública que se instalava na cidade (Moraes e Silva, 2011). Para alcançar tal intento, era necessário que os sócios seguissem parâmetros considerados civilizados, isto é, deveriam se inspirar em países que já tinham 
ascendido em direção a um ideário moderno. Dessa forma, surgia uma nova maneira de educar os corpos, fazendo com que imagens idealizadas de determinados comportamentos emergissem e adequassem esses corpos ao novo modelo social que aflorava nas principais cidades do Brasil e do mundo.

Nesse contexto, o Clube Curitibano passava a ter um papel fundamental na implantação de uma pedagogia corporal, principalmente por meio dos elementos da cultura física desenvolvidos em seu interior, fazendo com que determinados divertimentos passassem a ser cada vez mais regrados e institucionalizados:

De ordem da directoria communico aos srs. socios e suas exmas famílias que nas noites de 14 e 16 de fevereiro terão lugar dois grandes bailes á phantasia nos salões desta sociedade.

A directoria instituio três premios que serão conferidos ás phantasias do bello sexo que forem classificadas em $1^{\circ}, 2^{\circ}$ e $3^{\circ}$ lugares durante os dois bailes carnavalescos, e á juizo de uma commisão especialmente nomeada;

$$
\begin{aligned}
& \text { Os premios são denominados: } \\
& 1^{\circ} \text { Grande Premio Victoria } \\
& 2^{\circ} \text { Premio Clube Curitybano } \\
& 3^{\circ} \text { Premio Carnaval de } 1904
\end{aligned}
$$

A directoria pede o concurso de todos os srs. socios e suas exmas. famílias para que os dois bailes carnavalescos ostentem seo caracteristico e desejado explendor .

De Ordem do Sr. Presidente convido aos srs. socios e suas exmas familias para assistirem aos Bailes Carnavalescos que realizar-se ão em as noites de 21 e 23 do corrente. Pede-se aos srs. convidados o obsequio de apresentarem os seus cartões de ingresso á respectiva comissão de porta ( $A$ Republica, 1909, ed. 41, p. 2.).

As notícias demonstram o quanto os bailes passaram a ser mais especializados. Como exemplo desse aprimoramento, pode-se citar as premiações para os indivíduos que melhor desenvolvessem as gestualidades dançantes, acrescentando traços mais institucionalizados para os salões e incentivando 0 aperfeiçoamento de seus movimentos. Nota-se que tais procedimentos eram também um mecanismo de seleção de quem poderia entrar no Clube. A presença de convites e de responsáveis destinados a averiguar a veracidade dos invites evidenciavam a tentativa de manter a entidade numa condição seleta.

Foi nesse momento de efervescência dos bailes que a dança passou a ser ainda mais valorizada, trazendo consigo novos valores, além dos indispensáveis aspectos morais e comportamentais:

E o homem não cansa. A'quelle corpo, apparentemente alquebrado, move se de um lado para o outro com tanta precisão como se fora impulsionado por outro motor que não a vontade inquebrantavel de seu rijo temperamento. $O$ Delphin, pelo que vejo, pretende deminuir o volume do seu respeitável abdomen, a julgar-se pelos exercicios dançantes que frequentemente faz nas soirées do Club. E elle faz bem, porque, do modo que vai, ficará reduzido a 
graxa em menos de uma semana (Revista Club Curytibano, 1890, Ed. 18, p. 3).

Identifica-se que as práticas dançantes passaram a angariar apreciação em relação ao desenvolvimento da dimensão física, sendo vistas como uma prática para o fortalecimento do corpo, indicando que a cultura física permitiria o melhoramento de aspectos biológicos indo para além da dimensão intelectual e moral. Melo (2014) recorda que no mesmo período, no Rio de Janeiro, iniciativas relacionadas à dança foram estruturadas em outros espaços sociais. $O$ autor afirma que a dança passou a ser inserida nas escolas antes mesmo das ginásticas e dos esportes, visto as atividades dançantes eram compreendidas como agências educacionais.

Em Curitiba percebem-se elementos semelhantes, visto que homens, mulheres e crianças tentavam se enquadrar nesse anseio educacional, no qual a dança no Clube Curitibano emergia como principal ferramenta. Portanto, as práticas dançantes ocorridas na instituição passaram a ganhar qualidade de exercício físico, deixando de ser apenas um mero divertimento:

A dança é a arte de mover os pés a compasso ao som de instrumento, dando ao corpo uma desenvoltura agradavel, sem affetação. Todas as nações cultivam este bello exercicio que regulla os movimentos do corpo, desembaraço e firmeza no modo de pisar que tanto agrada em ambos os sexos [...] a dança não deixa de ser exercício gymnastico, portanto (Revista Club Curytibano, 1890, Ed. 16, p. 2).

Entende-se que cada passo dado pelo Clube Curitibano possibilita evidenciar ainda mais que os discursos da cultura física por meio da dança se tratavam de um processo mais amplo de educação do corpo. A cultura física, manifestada por meio das diversas festividades dançantes ganhava cada vez mais elementos institucionalizados. A dança passou a ser peça central de desenvolvimento social e ferramenta de educação corporal, contribuindo para a interiorização de gestualidades civilizadas, atreladas também ao fortalecimento físico e, principalmente, ligada a uma sociabilidade que poderia testar todas as sensibilidades adquiridas, podendo, no espaço do Clube, executar e melhorar as performances do corpo, se tornando uma forma de educar os sentidos e contribuindo para modelar os indivíduos às lógicas modernas que emergiam na capital paranaense.

\section{Considerações finais}

Com o intuito de compreender como se deu a implementação das festividades dançantes no Clube Curitibano, o presente artigo buscou também fornecer indícios dos primeiros elementos da cultura física realizados no interior da instituição. Para tal, não foi possível desvincular a junção do Clube com a capital paranaense, visto que o período analisado passava por processos de urbanização que acabaram por vincular seus membros e a própria entidade com a formação da capital como um importante centro urbano brasileiro. Com base nos vestígios encontrados, evidencia-se a importante contribuição do Clube Curitibano na 
construção de determinados comportamentos, que se objetivavam nos encontros dançantes realizados no interior da instituição.

Por meio dos valores da cultura física que se substanciavam nas festividades, nota-se que o Clube Curitibano contribuiu de alguma maneira na formação cultural dos habitantes da capital. Além disso, tais acontecimentos indicavam o embasamento de uma pedra angular potencializadora para a emergência de outros elementos da cultura física na instituição, aspectos que poderão vir a ser explorados em estudos futuros. Afinal, atividades desenvolvidas em espaços como esse externalizavam fortes indicativos de como os curitibanos, ao longo do processo de urbanização da cidade, transformaram seus hábitos e costumes. Nesse contexto, emergiram novas formas de se comportar e estabelecer relações interpessoais, que só atingiriam o patamar de algo útil se estivessem vinculadas a um discurso voltado aos aspectos modernos, em que os divertimentos precisavam ser institucionalizados, regrados e controlados, aspectos que o Clube Curitibano passou a implantar durante o recorte temporal aqui estudado, a ponto de se tornar base para que novas agremiações se estruturassem na cidade.

Por fim, entende-se que o presente artigo detalhou como um divertimento pode manifestar um variado espectro de técnicas e ferramentas que contribuíram para a formação de novos indivíduos e instituições, estes agora enquadrados em uma cidade de caráter mais moderno. Todavia, torna-se válido ressaltar que tal fenômeno não foi linear, visto que diversas variações e acontecimentos podem ter ocorridos. Para sanar tal carência, levanta-se a necessidade de novas análises e, consequentemente, novas interpretações acerca do período aqui explorado, bem como de maiores detalhes sobre cada elemento localizado como um importante fator para o estabelecimento dos benefícios da cultura física na agremiação e em outros espaços da cidade.

\section{Referências}

A República, 1900, Ed. 18, p. 4

A República, 1901, Ed. 149, p. 1.

A República, 1894, Ed. 185, p. 1.

A República, 1904, Ed. 21, p. 3.

A República, 1906, Ed. 87, p. 2.

A República, 1906, Ed. 90, p.2.

A República, 1907, Ed. 10, p. 2.

A República, 1909, Ed. 41, p. 2.

Benvenutti, A. F. (2004). As reclamações do povo na Belle Époque: a cidade em discussão na imprensa curitibana (1909-1916). Dissertação (Mestrado em História) - Programa de Pós-Graduação em História, Universidade Federal do Paraná, Curitiba.

Bourdieu, P. (2007). A distinção: crítica social do julgamento. São Paulo: Edusp; Porto Alegre: Zouk. 
Corrêa, A. S. (2009). Imprensa política e pensamento republicano no Paraná no final do XIX. Revista de Sociologia e Política, 17, (32),139-158.

Chalhoub, S. (2012). População e sociedade. In: CARVALHO, J. M. A construção Nacional (1830-1889). Rio de Janeiro: Objetiva, 36-81.

Cunha Filho, V. F. (1998). Cidade e sociedade: a gênese do urbanismo moderno em Curitiba (1889-1940). Dissertação (Mestrado em História) - Programa de PósGraduação em História, Universidade Federal do Paraná, Curitiba.

Dezenove de Dezembro, 1854, Ed. 7, p. 1.

Dezenove de Dezembro, 1863, Ed. 375, p. 2.

Dezenove de Dezembro, 1866, Ed. 657, p. 2.

Dezenove de Dezembro, 1873, Ed. 1403, p. 3.

Dezenove de Dezembro, 1884, Ed. 217, p. 2.

Dezenove de Dezembro, 1888, s.p.

Diário da Tarde, 1908, Ed 2892, p. 2.

Dogliotti, P. (2014). Acerca de la "Cultura Física" en la revista Uruguay-Sport: Archivos de la CNEF, Uruguay (1918-1926). Revista Brasileira de Ciências do Esporte, 36 (3), 608-616.

Dorfman, P. (2019). Clube Curitibano: uma cidade dentro da cidade de Curitiba. Disponível em: <https://www.gazetadopovo.com.br/vozes/parana-sa/clubecuritibano-uma-cidade-dentro-da-cidade-de-curitiba/>. Acesso em: 28 mai. 2019.

Freyre, G. (1974) Ordem e Progresso. Rio de Janeiro: Jorge Olympio.

Furtado, H. L., Quitzau, E. A., Moraes e Silva, M. (2018). Blumenau e seus imigrantes: apontamentos acerca da emergência de uma cultura física (18501899). Movimento, 24(2), 665-676.

Kirk, D. (1999). Physical culture, Physical education and relational analysis. Sport, Education and Society, 4 (1), 63-73.

Leandro, J. A. (2007). No fandango. Revista de História Regional, 12(1), 41-63.

Luca, T. R. (2008). A grande imprensa no Brasil da primeira metade do século XX. Brazilian Studies Association (BRASA), Atlanta, Georgia, 27-29.

Martins, A. L.; Luca, T. R. (2010). História da imprensa no Brasil. São Paulo: Editora Contexto.

Melo, V. A. (2001). Cidade "sportiva": primórdios do esporte no Rio de Janeiro. Rio de Janeiro: Relume-Dumará/Faperj.

Melo, V. A. (2014). Educação do corpo-bailes no Rio de Janeiro do século XIX: o olhar de Paranhos. Educação e Pesquisa, 40 (3), 751-766.

Melo, V. A. (2018). Preocupações com a educação physica. Educação e Pesquisa, 44, e175905.

Moraes e Silva, Marcelo. (2011). Novos modos de olhar outras maneiras de se comportar: a emergência do dispositivo esportivo da cidade de Curitiba (18991918). Tese (Doutorado em Educação). Programa de Pós-Graduação em Educação, Universidade Estadual de Campinas, Campinas. 
Moraes e Silva, M.; Quitzau, E. A. (2018). A cultura física na cidade de Curitiba: a emergência de uma pedagogia corporal (1899-1909). Revista Ciencias Sociales, 27(40),275-296.

Moraes e Silva, M; Quitzau, E. A.; Soares, C. L. (2018). Práticas educativas e de divertimento junto à natureza: a cultura física em Curitiba (1886-1914). Educação em Pesquisa, 44, e 178293.

Pastre, M. (2009). Clube Curitibano: representações de lazer na formação da sociedade curitibana. Tese (Doutorado em Educação Física). Programa de PósGraduação em Educação Física, Universidade Metodista de Piracicaba, Piracicaba.

Pereira, L. A. M. A dança da política: trabalhadores, associativismo recreativo e eleições no Rio de Janeiro da Primeira República. Revista Brasileira de História, v. 37(74),63-88.

Pereira, M. R. M. (1996). Semeando Iras Rumo ao Progresso. Curitiba: Editora da UFPR.

Pezzole, D. R. Jornal Dezenove de Dezembro. Trabalho de Conclusão de Curso de Design, Universidade Tuiuti do Paraná, Curitiba, 2006.

Pilato, M. (2018). As muitas sedes do Clube Curitibano. Gazeta do Povo. Disponível em: <https://www.gazetadopovo.com.br/haus/arquitetura/as-muitassedes-do-curitibano/>. Acesso em: 26 nov. 2018.

Reggianl, A. H. (2016). Cultura física, performance atlética e higiene de la nación: el surgimiento de la medicina deportiva en Argentina (1930-1940). Historia Crítica, 61, 65-84.

Revista Club Curytibano, 1890, Ed. 18, p. 3.

Revista Club Curytibano, 1890, Ed 16, p. 2.

Roquigny, P. (2011). Loisirsdansants de la bourgeoisie anglo-montréalaise. Transformation et persistance des lieux de pratique, 1870-1940. Urban History Review/Revue d'histoireurbaine, 40(1), 17-29.

Sêga, R. A. (2001). A capital Belle Époque: a reestruturação do quadro urbano de Curitiba durante a gestão do prefeito Cândido de Abreu (1913-1916). Curitiba: Aos Quatro Ventos.

Sevcenko, N. (1983). Literatura como Missão: tensões sociais e criação cultural na Primeira República. São Paulo: Brasiliense.

Scharagrodsky, P. A. (2014). Miradas médicas sobre la cultura física en Argentina (1880-1970). Buenos Aires: Editorial Prometeo.

Vaz, S. R. (2004). Vida social paranaense no início do século XX. Monografia apresentada para graduação no curso de História. Universidade Federal do Paraná, Curitiba.

Vigarello, G. (1999). História das Práticas de Saúde: a saúde e a doença desde a Idade Média. Lisboa: Editorial Notícias.

Weber, E. J. (1988). França fin-de-siècle. São Paulo: Companhia das Letras.

Westphalen, C. M. (1983). Lazeres e festas de outrora. Curitiba: SBPHPR. 


\section{Notas}

1 Atualmente, a revista tem edições mensais. Para mais informações, acesse: https://www.clubecuritibano.com.br/revistas/

${ }^{2}$ Essas informações foram acessadas por meio do arquivo histórico do próprio Clube Curitibano, em sua sede denominada Concórdia. 